\title{
O LUGAR COMO CATEGORIA DE ANÁLISE NA GEOGRAFIA E SUA CONTRIBUIÇÃO PARA ABORDAGENS DIDÁTICAS NA CARTOGRAFIA ESCOLAR
}

The place as a category of analysis in Geography and its contribution to didactic approaches in School Cartography

\section{El lugar como categoría de análisis en Geografía y su contribución a los enfoques didácticos en Cartografía Escolar}

Maurício Rizzatti

Mestre em Geografia pela UFSM geo.mauricio.rizzatti@gmail.com

\author{
Natália Lampert Batista \\ Pós-doutorado em Geografia UFSM \\ natilbatista3@gmail.com \\ Elsbeth Léia Spode Becker \\ Doutorado em Agronomia pela UFSM \\ elsbeth.geo@gmail.com \\ Roberto Cassol \\ Doutorado em Geografia USP \\ rtocassol@gmail.com
}

Artigo recebido em 19/05/2020 e aceito em 04/02/2021

DOI: $10.12957 /$ tamoios.2021.51120

\section{RESUMO}

Ao pensar o ensino de Geografia e a Cartografia Escolar não se pode perder de vista as distintas categorias de análise que permeiam a ciência geográfica, pois é nessa interrelação que o professor dessa componente curricular pode pensar criticamente $o$ desenvolvimento de metodologias de ensino-aprendizagem. Com base nisso, esse trabalho tem por objetivo apresentar a evolução do conceito de lugar nas escolas geográficas e a contribuição dessa categoria de análise da Geografia para algumas abordagens metodológicas da Cartografia Escolar em sala de aula. Para o seu desenvolvimento, realizou-se a abordagem teórica da categoria de análise lugar e após apresentou-se as metodologias voltadas à Cartografia Escolar. Conclui-se que o estudo do lugar, baseado na Cartografia Escolar, é eficaz para o desenvolvimento do pensamento espacial e para o estimulo ao raciocínio geográfico, centrais ao ensino de Geografia na contemporaneidade.

Palavras-chave: Ensino de Geografia. Propostas didáticas. Pensamento Espacial. 


\begin{abstract}
When thinking about teaching Geography and School Cartography, one cannot lose sight of the different categories of analysis that permeate geographic science, as it is in this interrelation that the teacher of this curricular component can critically think about the development of teaching-learning methodologies. Based on this, this work aims to present the evolution of the concept of place in geographic schools and the contribution of this category of analysis of Geography to some methodological approaches of School Cartography in the classroom. For its development, the theoretical approach of the place analysis category was carried out and afterwards the methodologies focused on School Cartography were presented. It is concluded that the study of the place, based on School Cartography, is effective for the development of spatial thinking and for stimulating geographic reasoning, central to the teaching of Geography in contemporary times.
\end{abstract}

Keywords: Geography teaching. Didactic proposals. Spatial Thinking.

\title{
RESUMEN
}

Al pensar en enseñar Geografía y Cartografía Escolar, uno no puede perder de vista las diferentes categorías de análisis que impregnan la ciencia geográfica, ya que es en esta interrelación que el maestro de este componente curricular puede pensar críticamente sobre el desarrollo de metodologías de enseñanza-aprendizaje. En base a esto, este trabajo tiene como objetivo presentar la evolución del concepto de lugar en las escuelas geográficas y la contribución de esta categoría de análisis de geografía a algunos enfoques metodológicos de la cartografía escolar en el aula. Para su desarrollo, se llevó a cabo el enfoque teórico de la categoría de análisis de lugares y luego se presentaron las metodologías enfocadas a la Cartografía Escolar. Se concluye que el estudio del lugar, basado en la cartografía escolar, es efectivo para el desarrollo del pensamiento espacial y para estimular el razonamiento geográfico, fundamental para la enseñanza de la geografía en los tiempos contemporáneos.

Palabras clave: Enseñanza de geografía. Propuestas didácticas. Pensamiento espacial. 


\title{
Introdução
}

Desde os tempos mais remotos, a humanidade faz uso de conhecimentos geográficos aplicados em suas atividades cotidianas. Em um primeiro momento, a Geografia era utilizada, principalmente para desenhar trajetos percorridos e para informar os recursos existentes para serem explorados em uma determinada região. Os povos primitivos, mesmo sem o domínio da escrita, utilizavam desenhos (figuras rupestres) para representar o que havia nos locais onde habitavam ou onde se deslocavam (nômades). Além disso, esses povos conheciam os fenômenos da natureza, a relação com o clima, o solo, a hidrografia, que eram muito relevantes para a sua sobrevivência.

Desta maneira, a localização no espaço é algo primordial para esses povos, que começam a produzir "mapas mentais" em placas de argila, como no caso do mapa de GaSur, demonstrando a importância de se conhecer onde se habita e possui mais segurança em caso de ataque. A "Geografia científica" se origina no pensamento grego. Sua originalidade é de ter imaginado um procedimento de orientação e localização fundado em referências astronômicas (CLAVAL, 2011).

Para Andrade (1987) os gregos:

\begin{abstract}
Ao mesmo tempo em que se ampliava o conhecimento do espaço geográfico, aguçando a pesquisa dos sistemas de relação entre a sociedade e a natureza sistemas agrícolas, técnicas de uso do solo, relacionamento entre as cidades e o campo, relações entre as classes sociais e entre o Poder e o povo -, desenvolvia-se também a curiosidade sobre as características naturais, os sistemas de montanha, os rios com os seus variados regimes, a distribuição das chuvas, a sucessão das estações do ano etc. (ANDRADE, 1987, p. 24).
\end{abstract}

Os conhecimentos caracterizados como geográficos estavam fragmentados e desorganizados, cabendo a filosofia, a matemática e a física as discussões e debates pertinentes. A organização científica ocorreu somente no século XIX, na Alemanha. (COSTA; ROCHA, 2010).

Assim, percebemos que desde a civilização mais remota, a preocupação em se orientar no espaço era de extrema importância. Neste momento, que o termo "local" é sinônimo de "lugar". Conforme o minidicionário Aurélio (citado por FERREIRA, 2001, p. 465), "[...] lugar é conceituado como espaço ocupado; sitio ou ponto referido a um fato; posição, situação; posição determinada num conjunto, numa série". Então o lugar passa a ser usado como ponto de referência, caracterizado por uma latitude e longitude, ligado a noção de individualidade das parcelas do espaço. Por outro lado, o lugar também é o locus da identificação do sujeito com o mundo, em uma visão humanística, o lugar é sentimento e apropriação do espaço de vivência. Todas essas concepções podem ser articuladas com a Cartografia Escolar, como forma de potencializar o ensino de Geografia.

Com base no exposto, esse trabalho tem por objetivo apresentar a evolução do conceito de lugar nas escolas geográficas e a contribuição dessa categoria de análise da Geografia para algumas abordagens metodológicas da Cartografia Escolar em sala de aula. 


\section{O lugar como categoria de análise nas escolas geográficas}

A humanidade utilizou desde seus primórdios de conhecimentos geográficos, embora a Geografia ainda não fosse considerada ciência. A sistematização da mesma parte das obras de Alexander von Humboldt e Karl Ritter. Em meados do Século XIX, a Geografia

[...] passou a ter status de ciência, sendo, a partir dessa época, ensinada e praticada nas universidades. Formou-se então uma corrente de pensamento no seio da geografia que ficou conhecida como "escola alemã", cuja característica central era o fato de ser iminentemente determinista e naturalista (CAMARGO; REIS JÚNIOR, 2007, p. 83).

Esses pesquisadores construíram os alicerces fundamentais para o embasamento de uma geografia científica, incidindo no desenvolvimento dessa ciência a partir dos anos de 1870. Os estudos de Humboldt contribuíram para a configuração de conhecimentos utilizados hoje pela Geografia Física. Em sua viagem para a América do Sul, na qual descreveu as principais características físicas e humanas dos lugares por onde passou, bem como a classificação de algumas espécies, relacionando-as com a sua distribuição geográfica, como, por exemplo, a latitude e altitude (RIZZATTI, 2016). Nessas viagens, Humboldt teve a preocupação em entender as diferenças e similaridades entre as paisagens da superfície terrestre, usando para isso o método comparativo (COSTA; ROCHA, 2010).

O mencionado método foi de relevância primordial, apresentando a distribuição espacial das espécies de animais e vegetais, relacionando-os a padrões climáticos de precipitação e temperatura. O determinismo geográfico tem seu princípio baseado no positivismo lógico e considera a natureza como um agente ativo sobre o homem, isto é, considerando os elementos naturais, principalmente o clima, como influencia o comportamento humano. Nesse sentido, tem sua preocupação centrada em estabelecer leis gerais que explicassem o mundo em que vivia.

Assim, os estudos dos fenômenos devem se restringir aos aspectos visíveis, mensuráveis e palpáveis, caracterizando a Geografia como uma ciência empírica, pautada na observação, sendo essa a única forma de conhecimento possível. Os procedimentos de análise da Geografia Tradicional se baseiam na observação, descrição, enumeração, comparação e, por fim, a conclusões gerais e a fundamentação das leis. Nesse momento, a indução ${ }^{1}$ é vista como a única maneira para se chegar à explicação científica.

Como oposição ao determinismo alemão, proposto por Friedrich Ratzel e que defendia que o meio era determinante ao homem, surge na França no final no século XIX outro paradigma da Geografia Clássica: o possibilismo. Sua visão é incluir o homem no meio natural, não mais fazendo a natureza como elemento dominante do comportamento humano. A grande contribuição para o possibilismo foi do francês Vidal de La Blache, que definiu o objeto da Geografia como sendo a relação homem-natureza, na perspectiva da paisagem (MORAES, 1987). La Blache admitia que o meio exerce alguma influência sobre o homem, mas a sociedade, dependendo das condições técnicas e dos recursos disponíveis poderia exercer influência sobre o meio (ANDRADE, 1987).

Como os estudos estavam voltados para pequenas áreas, surge nesse momento a Geografia Regional, levando em consideração os aspectos físicos e sobrepondo a eles, aspectos humanos e econômicos, admitindo que o meio físico serve de suporte para os seres humanos, e a sociedade modifica esse meio, construindo e extraindo recursos para a sua sobrevivência (COSTA; ROCHA, 2010). 
A partir do exposto, Rodrigues (2008) discute que a Geografia Regional compartimenta

[...] o estudo geográfico em quadros físicos, humanos e econômicos. Assim, tem-se, por exemplo, nos trabalhos monográficos e regionais: a localização da área, por meio de projeções cartográficas; o quadro físico; como relevo, solo, hidrografia, clima vegetação etc.; a formação histórica de ocupação humana do território; a estrutura agrária; a estrutura urbana; a estrutura industrial etc. Finalmente, apresenta-se uma conclusão, com um conjunto de cartas, objetivando demonstrar uma relação entre os elementos humanos e naturais da região (RODRIGUES, 2008, p. 86).

Inicialmente, nos enfoques da Geografia a relação homem/natureza é meramente descritiva. Os conceitos privilegiados durante a Geografia Tradicional eram região e paisagem (CORRÊEA, 2003), sendo o primeiro presente no conhecimento elaborado desde a Antiguidade, sendo bastante usado para apresentar as diferenças e os contrastes da superfície da Terra, descritivamente.

A categoria lugar na Geografia Clássica do início do século XX, era utilizado em sentido locacional e usava-se para definir a Geografia: "A Geografia é a ciência dos lugares e não dos homens" (LA BLACHE, 1913 apud HOLZER, 1999). O conceito de lugar na Geografia Tradicional, "foi definido de acordo com as características naturais e culturais próprias de uma determinada área. Estava ligado à noção de localização" (COSTA; ROCHA, 2010). Assim, o lugar era vinculado ao espaço absoluto, isto é, por coordenadas geográficas/geodésicas, onde o estudo e a confecção de mapas eram um dos fundamentos da disciplina. Nesse período, a partir de uma concepção positivista, o lugar foi eventualmente estudado pelos geógrafos, mas sempre em um plano secundário (HOLZER, 1999).

Conforme exposto até aqui, a Geografia teve como paradigmas norteadores até a metade do século XX: o determinismo alemão e o possibilismo francês. Segundo Kuhn (1989, p. 14-15), as escolas são guiadas por algo muito semelhante a um paradigma e "existem circunstâncias, [...] nas quais dois paradigmas podem coexistir pacificamente [...]", como ocorre na Geografia Clássica. Os mesmos, com o passar dos anos, eram incapazes de fornecer subsídios afim de responder os estudos da época, passando por diversas reformulações de suas doutrinas teóricas, visto que, as mesmas entram em crise na medida que não conseguem resolver os problemas levantados em determinado período (KUHN, 1989).

Nesse sentido, a Geografia não podia escapar às enormes transformações ocorridas em todos os domínios científicos após 1950 (SANTOS, 1986), levando em consideração ao desenvolvimento da produção capitalista e tecnológica que se apresentava, buscou-se novas abordagens metodológicas. Essas modificações somam-se as críticas recebidas pela Geografia Tradicional. Assim, segundo Camargo e Reis Junior

\footnotetext{
Denomina-se Geografia "Teorética e Quantitativa" ou Geografia "Neopositivista" a corrente que começou a se formar logo após a Segunda Guerra Mundial e que terminou por trazer profundas modificações teóricas e metodológicas. Esta escola se caracterizou pelo emprego maciço das técnicas matemático-estatísticas na geografia, provocando uma verdadeira "revolução" no seio dessa ciência [...] (CAMARGO; REIS JÚNIOR, 2007, p. 84).
}

Desta maneira, essa nova fase da ciência geográfica adota a linguagem matemática e estatística afim de expressar resultados claros, apontando a quantidade de variáveis existente em determinadas porções do território. Então, tem-se a preocupação com a organização espacial, levando em consideração a escala de fenômenos e os elementos 
presentes em diferentes estruturas. A transformação da Geografia Clássica para a Neopositivista após a segunda metade do século XX, ocorre através da "adoção de uma postura pragmática de técnicas estatísticas e da geometria, a utilização de regras e princípios da economia neocapitalista e a assunção do positivismo logico como método de apreensão do real" (DE CAMPOS, 2011, p. 463). A obra de Walter Christaller (Teoria dos Lugares Centrais) apresenta a quantificação em uma transformação filosófica da Geografia, além disso uma serie de teorias espaciais, como Teoria dos Círculos Concêntricos, a Teoria dos Pólos de Crescimento, o Modelo Centro Periferia, a Estruturação Funcional e Hierárquica das Cidades, entre outros.

No Brasil, serve como exemplo o fato dos planejadores acreditarem na criação de um grande polo (São Paulo) que irradiava desenvolvimento, em círculos concêntricos, para outras áreas e região. Ainda, projetam uma nova capital, uma cidade como "máquina de morar", animada pelo espírito da geometria, ordem e eficácia. (DE CAMPOS, 2011). No ano de 1956, início do governo de Juscelino Kubitschek, seu Plano de Metas adotou uma política para expandir a economia brasileira, integrando-a principalmente ao capitalismo dos Estados Unidos da América. Nesse sentido, a "Geografia Quantitativa é a reformulação necessária frente às novas exigências do capitalismo" (DE CAMPOS, 2011, p. 463).

Dois foram os centros de principal adoção: Rio Claro/SP (com o Boletim de Geografia Teorética) e no Rio de Janeiro com a Revista Brasileira de Geografia do Instituto Brasileiro de Geografia e Estatística, ressaltando-se que na Nova Geografia o método utilizado passa a ser a dedução, partindo de teorias até enunciados particulares. Nesse período, além da paisagem, o território desaparece das interpretações quantitativas e o espaço surge como conceito estrutural. A Região por sua vez, passa a ser vista como um recorte de área definida a partir de critérios de homogeneidade e/ou de relações funcionais (como os cinturões de desenvolvimento agrícola dos Estados Unidos "belts"), muito difundida nesse momento. O lugar continua ainda atrelado a aspectos locacionais. A utilização de procedimentos quantitativos é de extrema relevância, mas essa aplicação ocorreu de maneira exacerbada, abandonando os aspectos qualitativos, com a falsa impressão que todos poderiam ser quantificados (DE CAMPOS, 2011).

Os geógrafos neste período começam a criticar o paradigma da quantificação e se colocam radicalmente contrário a ele. No início da década de 1970 surge então a denominada Geografia Crítica, com três tendências principais: radical, humanística e idealista (CHRISTOFOLETTI, 1985). Nesta época, por influência do marxismo, os geógrafos assumem uma nova orientação em suas práticas políticas buscando romper com a neutralidade pregada pelo positivismo e se envolver mais em propostas de mudanças sociais, preocupados com a transformação da ordem social. (COSTA; ROCHA, 2010).

A Geografia Humanista ou da Percepção surge em contraponto ao neopositivismo, partindo como princípio de estudos fenomenológicos. Segundo De Campos (2011, p. 491) "o positivismo gerou a crise das ciências humanas e forçou o repensar dos fundamentos destas disciplinas, retomando a relação sujeito-objeto, e procurando superar o dualismo psicofísico, a separação do homem-mundo, provocado pelo racionalismo e pelo empirismo".

A Geografia da Percepção tem por objetivo realçar os aspectos humanos - valores, significados, propósitos - ressaltando "a experiencia do indivíduo ou do grupo, visando compreender o comportamento e as maneiras de sentir das pessoas em relação aos seus lugares" (CHRISTOFOLETTI, 1985b, p. 22).

Nesse sentido, a Geografia Humanística tem como filosofia norteadora a fenomenologia, que é conceituada como uma "descrição de todos os fenômenos, ou 
'eidos' ou essências, ou significação de todas essas realidades: materiais, naturais, ideais, culturais" (CHAUÍ, 1994, p. 239). O conhecimento se dá com base nos sentidos, pois a consciência e o vivido não se encontram fixados no objeto e a intencionalidade " [...] é uma relação entre o fenômeno - o parecer do objeto - e a vivência em que o objeto aparece" (ARAÚJO, 2007, p. 67).

Foi a partir desse momento que o lugar como categoria de análise na Geografia ganha destaque. Carl Ortwin Sauer talvez tenha sido o primeiro a desvincular o lugar deste sentido estritamente locacional. Isto porque ele via a disciplina geográfica como algo que estava "além da ciência", ou seja, que não devia necessariamente trilhar os caminhos preconizados pelos positivistas (HOLZER, 1999).

O estudo da Geografia para Sauer estava vinculado ao conceito de paisagem cultural, no qual "a cultura é o agente, a área natural é o meio, a paisagem cultural é o resultado." (SAUER, 1998, p. 59). A paisagem cultural atrela fortes elementos subjetivos, e esses elementos remetiam ao conceito de lugar, como se pode depreender da passagem a seguir: A literatura da Geografia, inicia-se como parte das primeiras sagas e mitos, vividas como o sentido do lugar e da luta do homem com a natureza (HOLZER, 1999). Levando suas propostas a uma atitude intelectual mais radical, Sauer incorporaria integralmente a subjetividade que estava implícita no conceito de lugar: Os fatos da Geografia são fatos do lugar; sua associação origina o conceito de paisagem (HOLZER, 1999). Deste modo, as características de cada indivíduo acabam se ressaltando, demonstrando os aspectos mais significativos, ligado ao conceito de região em caso de recorte espacial demonstrando os atributos de cada lugar.

Juntamente com Sauer, outro autor que afasta o lugar apenas como sendo locacional é Lukermann, ao enfatizar que a tarefa da Geografia não é mais apenas inventariar o conteúdo das áreas, mas analisar o modo de ver o mundo das pessoas que ali se encontram. Desse modo, o conceito de lugar proposto pelo autor, começa a se aproximar do conceito de mundo, enunciado pelos fenomenólogos (HOLZER, 1999).

Assim, podemos verificar que o lugar ganha um significado atrelado ao ser humano, ou seja, aquele que o indivíduo se encontra integrado ou que pertence aquele meio. A abordagem geográfica passou, então, a adotar uma intersecção com a Psicologia, tratando da afetividade do indivíduo na sua relação com o lugar. O sujeito estabelece com o seu lugar com as experiências do cotidiano. Nessa perspectiva, o geógrafo sinoestadunidense Yi-fu Tuan, apresenta o termo topofilia, que compreende um estudo da percepção, atitudes e valores, sendo o elo afetivo da pessoa e seu lugar.

Para Tuan (1980), "topofilia" é

[...] um neologismo, útil quando pode ser definido em sentido amplo, incluindo todos os laços afetivos dos seres humanos com o meio ambiente material. Estes diferem profundamente em intensidade, sutileza e modo de expressão. A resposta ao meio ambiente pode ser basicamente estética: em seguida, pode variar do efêmero prazer que se tem de uma vista até a sensação de beleza, igualmente fugaz, mas muito mais intensa, que é subitamente relevada. A resposta pode ser tátil: o deleite ao sentir o ar, água, terra. Mais permanentes e mais difíceis de expressar, são os sentimentos que temos para com um lugar, por ser o lar, o locus de reminiscências e o meio de se ganhar a vida (TUAN, 1980, p. 107).

Dessa maneira, percebe-se que Tuan relaciona os sentimentos em relação ao lugar com os sentidos humanos: audição, visão, olfato e tato, ao pertencimento do sujeito e o seu lugar, isto é, que o indivíduo está ambientado por uma série de relações e sentimentos, demonstrando que o "ser humano percebe o mundo simultaneamente através de todos os 
seus sentidos" (TUAN, 1980, p. 12), devendo-se também considerar a cultura, para se perceber o espaço de acordo como as pessoas o constroem.

$\mathrm{O}$ autor destaca ainda que:

\begin{abstract}
"Espaço" e "lugar" são termos familiares que indicam experiências comuns. Vivemos no espaço. Não há lugar para outro edifício no lote. As Grandes Planícies dão a sensação de espaciosidade. O lugar é a segurança e o espaço é a liberdade: estamos ligados ao primeiro e desejamos o outro. O que é lar? É a velha casa, o velho bairro, a velha cidade ou a pátria. Os geógrafos estudam lugares. Os planejadores gostam de evocar "um sentido de lugar". Essas são expressões comuns. Tempo e lugar são componentes básicos do mundo vivo, nós os admiramos como certos. Quando, no entanto, pensamos sobre eles, podem assumir significados inesperados e levantam questões que não ocorreria indagar (TUAN, 2013, p. 11).
\end{abstract}

Assim, "o lugar é um tipo de objeto. Lugares e objetos definem o espaço, dandolhe personalidade geométrica. [...] Atraem ou repelem em grau variado de nuanças. Preocupar-se com eles, mesmo momentaneamente, é reconhecer sua realidade e valor" (TUAN, 2013, p. 28). Todos os lugares são pequenos mundos, podendo se tornar símbolos públicos ou campos de preocupação, mas o poder dos símbolos para criar lugares depende das emoções humanas que vibram nos campos de preocupação ou de afeição (TUAN, 2013).

De forma similar, no livro Espaço e Lugar (1983), procura analisar o espaço e lugar dentro de uma perspectiva humana. Em uma abordagem mais geral, parte do princípio que são termos familiares, entendidas como as diferentes maneiras pelas quais uma pessoa conhece e constrói a realidade (DE CAMPOS, 2011). Segundo Tuan (1983, p. 6) o "'Espaço' é mais abstrato que 'lugar'. O que começa com espaço indiferenciado transforma-se em lugar à medida que o conhecemos melhor e o dotamos de valor. [...] A partir da segurança e estabilidade do lugar estamos cientes da amplidão, da liberdade e da ameaça do espaço, e vice-versa".

Lugar é um espaço não delimitado, onde nós vivemos, trabalhamos, estudamos conhecemos as pessoas, pressupõem uma certa vivência, uma certa identidade, envolvendo o sentimento de pertença e intencionalidade. O estudo do lugar passou por modificações ao longo do tempo com a sucessão das diferentes correntes teóricas da Geografia. Iniciou-se como uma referência locacional e passou a ser, efetivamente, usado como categoria de análise essencial da disciplina a partir da consolidação dos estudos da Geografia Humanista.

A partir da década de 1980, o lugar pode ser conceituado como o espaço percebido, ou seja, uma determinada área ou ponto do espaço da forma como são entendidos pela razão humana. Seu conceito também se liga ao espaço afetivo, aquele local em que uma determinada pessoa possui certa familiaridade ou intimidade, como uma rua, uma praça ou a própria casa, por se constituir de um centro de significados espaciais pessoais ou intersubjetivos o lugar não possui escala definida (HOLZER, 1999).

Atualmente existem discussões sobre "subcategorias" do conceito de lugar como, por exemplo, o não-lugar e entre-lugar. O entre-lugar trata-se de uma negação, ou seja, o lugar não é visto através da relação do sujeito e o espaço, onde o mesmo tem um pertencimento e apego adquiridos pela experiência cotidiana, ou ainda pode ser visto como um terreno onde são vividas as práticas sociais, é onde se situa o cotidiano, é o espaço praticado (FERREIRA, 2000).

O não-lugar, marcado por Webber (1964), considerava que a acessibilidade de um determinado lugar é mais importante do que a proximidade com ele. Esta foi a 
compreensão inicial de não-lugar. Logo, o não-lugar não caracteriza um afeto do indivíduo com o meio, não significando algo para a vida das pessoas. Assim, o não-lugar é atrelado ao deslocamento (as vias de circulação), centros comerciais, que não desencadeiam experiências compartilhadas. Nesse sentido Callai $(2014$, p. 103) coloca o não- lugar como "espaços vazios de conteúdo e de história. São neutros, transitórios, em geral, de uma arquitetura de desnudamento", isto é, espaço em que se transita, porém com intenção de chegar a outros lugares. Da mesma maneira, Castrogiovanni $(2009$, p. 7) aborda que "o Não-Lugar parece ser a simples negação do Lugar. O Lugar e o Não-Lugar são, antes, polaridades fugidias: o primeiro não ser completamente apagado e o segundo nunca se realiza totalmente".

Do ponto de vista turístico, Castrogiovanni (2009, p. 7) aborda o Entre-Lugar "como sendo a lugarização do Espaço Geográfico, substanciada pelo Sujeito visitante na dialogicidade estabelecida entre o seu Lugar (Lugar conhecido) e o Lugar/Não-Lugar visitado (desconhecido)". Desta maneira, o Entre-Lugar parece ser o Lugar provisório que estabelece o Sujeito Turístico, cada vez mais atuante com a Globalização (CASTROGIOVANNI, 2009).

Fazendo uma sistematização do que foi exposto, o geógrafo argentino Gustavo Buzai, no trabalho "Geografia y tecnologias digitales del siglo XXI: Uma aproximación a las nuevas visiones del mundo y sus impactos científico-tecnológicos" (2004), apresenta um breve históricos dos paradigmas que nortearam a Geografia desde sua sistematização como ciência no final do século XIX. Mostra a renovação Geografia no passar dos anos e que ocorre em formas de ondas que variam em duração de tempo: curtas ( 20 a 25 anos) e largas (100 anos).

O desenvolvimento do pensamento geográfico é modelado através da coexistência de ondas curtas e largas (Figura 1), com períodos de auge e "estacionamento" dos paradigmas para análise da realidade (BUZAI, 2015). As ondas com periodicidade curta possuem duração média de duas décadas e são caracterizadas por uma sequência positivista (P), influenciado, em um primeiro momento pela Biologia (por volta de 1900), ao positivismo matemático (em meados dos anos de 1950 com a Geografia Quantitativa) e uma final ligada aos avanços na área da informática (relacionada com a Geografia Crítica). Outra sequência de curta duração é a histórica (H), onde o valor de cada uma das ondas é vinculado a um período de crise. O primeiro vale está relacionado a crise de 1929, onde a Geografia Regional passava por uma atualização/reformulação. O segundo vale da onda ocorre por meados dos anos de 1970, na transição da quantificação para a crítica, com um caráter mais social, ligada a pós-modernidade. 


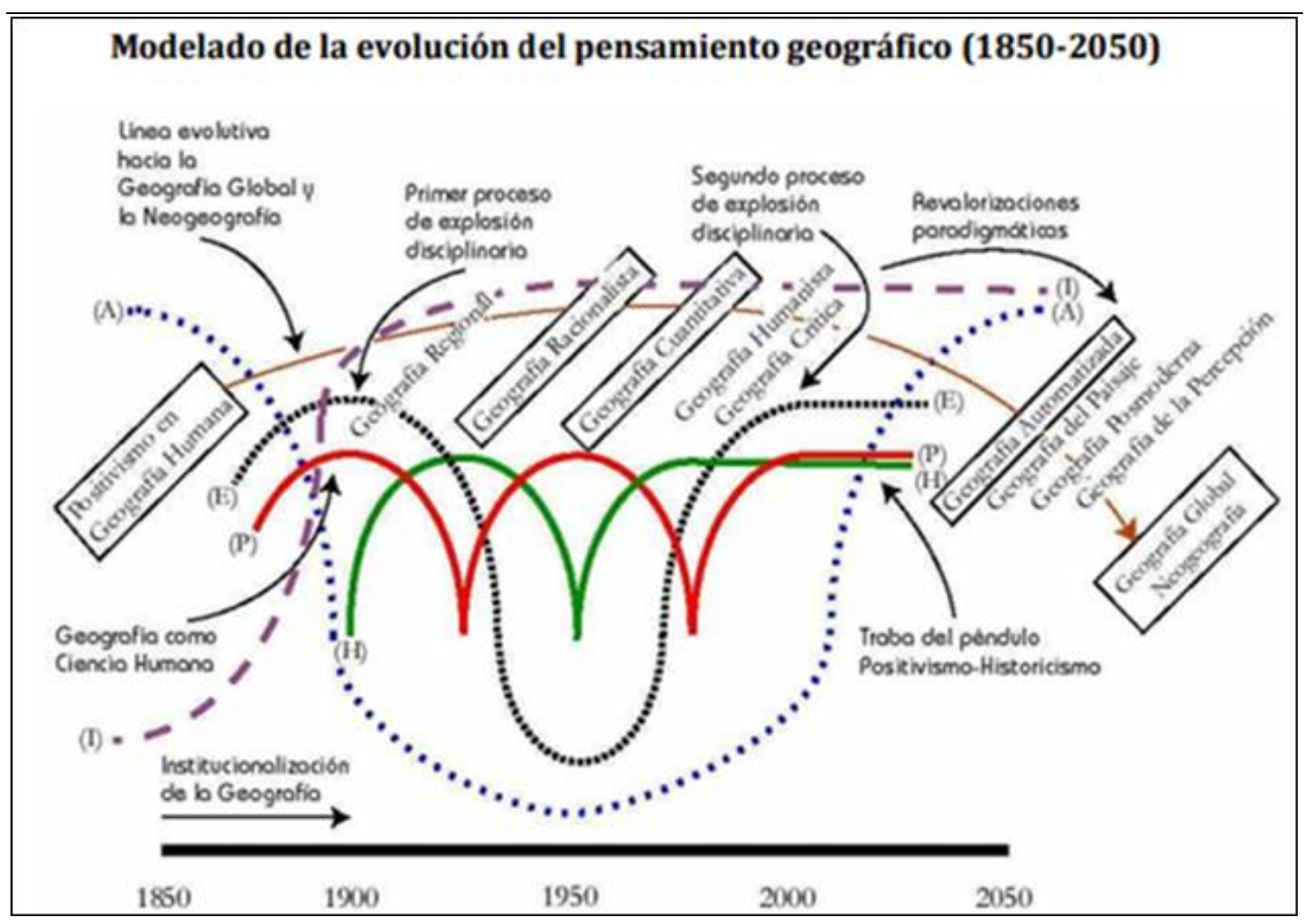

Figura 1 - Evolução do pensamento geográfico. Fonte: Buzai, 2015.

A onda com duração média de 100 anos, segundo Buzai (2015), possui como característica a explosão disciplinaria (E). Conforme o referido autor, a primeira explosão disciplinaria ocorreu no final do século XIX, quando a Geografia apresenta o seu objeto de estudo para a aparição de novas ciências e cem anos depois, quando ingressa aos computadores e tecnologia, se torna global ao resto das ciências (BUZAI, 2015). Destacase que hoje a Geografia incorpora os Sistemas de Informação Geográfica (SIG) que são resultado do desenvolvimento da ciência ao longo dos últimos 100 anos, sendo aplicados em muitas outras disciplinas. Nesta perspectiva, Geografia já não fornece objetos de estudo para outras ciências, mas sim as formas de ver a realidade com uma visão espacial por meio de seus diversos conceitos e métodos.

A influência das tecnologias no campo da informática é constante na sociedade e, por consequência, tem seus efeitos sentidos na atividade geográfica. Tomando os conceitos da tecnologia da informação e aplicando os conhecimentos teóricos e metodológicos produzidos por ela se criam uma nova especialidade na Geografia: a Geoinformação. Esta nova especialidade surge para atender as demandas de um mundo real que se torna um modelo digital e apresenta possibilidades variadas do manejo da informação geográfica que até então era inesperado. (BUZAI, 1998).

Desta maneira, a geotecnologia cria uma nova visão do espaço geográfico e seus modelos representam um amplo impacto no modo predominante de ver a realidade em análises espaciais no final do século XX. Já no início do século XXI, a Geotecnologia se consolida como um novo paradigma, uma vez que transforma a maneira de ver a realidade por meio da análise espacial e exporta isto para as outras áreas de conhecimento. Este novo paradigma não é produto de especulação teórica. Surge do trabalho interdisciplinar de pesquisadores por meio do uso de novas tecnologias e da relação recíproca entre Ciência e Tecnologia em distintos momentos. Por fim, este paradigma não é apenas um 
paradigma da Geografia e sim um paradigma geográfico de alcance interdisciplinar e a total serviço do homem e da sociedade. (BUZAI, 2004).

O atual paradigma, já amplamente incorporado ao cotidiano da atual sociedade, no mundo dos iPhones e iPads, é a localização instantânea de qualquer lugar do mundo por meio do mapeamento digital, também chamado de cartografia digital, cujo processo permite compilar e formatar um conjunto de dados em uma imagem virtual. A imagem virtual, o mapa, é um instrumento de localização espacial de grande alcance na sociedade atual, em todos os segmentos econômicos e políticos, e de grande importância para a Cartografia Escolar e a leitura de mapas. Portanto, a educação cartográfica é de extrema importância, pois auxilia os estudantes a entender o que o signo quer dizer na representação gráfica e correlacionar com o seu espaço vivido e com os espaços de outras culturas no mundo.

\section{Possibilidades metodológicas para Cartografia em sala de aula}

Após a segunda metade do século XX, o mundo passa por grandes revoluções científicas e tecnológicas, tornando-se globalizado através de redes em escala global, gerando uma série de informações que invadem o nosso dia a dia, mesmo que de maneira desigual. Deste modo, a tecnologia vem ganhando destaque a partir de então, pelo número crescente de pessoas utilizando computadores portáteis e smartphones, empregando aplicativos de mapas digitais (e GPS) cotidianamente para se deslocar, como o Google Maps, Waze, Maps-me e Open Street Map, embora a ideia que isso esteja ligado a uma ciência denominada Cartografia, é vaga. Toda essa infinidade de possibilidades cartográficas permite que o estudo do lugar se dê de formar mais ampla, possibilitando compreendê-lo em sua relação com o global e com as noções de topofilia e topofobia dos sujeitos.

Partindo dessa premissa, a utilização da Cartografia no ambiente escolar para estudo do lugar vai além de ensinar o aluno a "ler mapas", mas também devem ser desenvolvidas noções de orientação espacial, proporção, bem como de arte, através das convenções utilizadas a fim de representar o mundo tridimensional em uma superfície plana (bidimensional), além da variável cor, forma e espessura, promovendo noções do ato de mapear, relacionando com os elementos conhecidos pelos estudantes, de modo que os temas abordados tenham significado para os mesmos. Essas dimensões da Cartografia ficam muito evidentes na nova Base Nacional Comum Curricular (BNCC) que pauta os conhecimentos da Geografia no desenvolvimento do pensamento espacial e do raciocínio geográfico, bem como enfatiza a necessidade de que os conhecimentos geográficos tenham sentido para os estudantes.

Dessa forma,

Partimos da concepção de que o pensamento espacial mobiliza e desenvolve o raciocínio geográfico, pois se trata de inserir os princípios e conceitos estruturantes para análise do espaço e sua dinâmica, por exemplo, escala, extensão, localização, as relações entre as unidades de medida, as diferentes formas de calcular a distância (milhas, tempo de viagem, custos de viagem), os sistemas de coordenadas, a natureza dos espaços (bidimensionalidade e tridimensionalidade). Trata-se de buscar fundamentos para consolidar a Geografia no currículo escolar por meio de novas abordagens de aprendizagem, integrando a didática com os conceitos e princípios geográficos. Trata-se, também, de dar força a educação geográfica, por meio da compreensão dos fenômenos e situações geográficas vivenciadas pelos alunos 
em seu cotidiano, relacionando-os e compreendendo-os. (CASTELLAR; JULIASZ, 2017, p. 162).

Nesse sentido, as pessoas convivem com mapas e aplicativos de navegação que utilizam sinais emitidos por satélites artificiais, podendo também ser desenvolvido seu uso em fins educacionais e para o estudo do lugar, ou seja, da escola, do bairro, da comunidade de inserção do estudante. A escola, por sua vez, deve utilizar esses recursos com diversas finalidades, visto que permitem ser trabalhados em vários contextos, como por exemplo para uma compreensão do espaço vivido de seus alunos. No momento atual, em que as transformações ocorrem com muita rapidez por meio dos incrementos tecnológicos, a escola, no papel de formadora de cidadãos, precisa rever suas práticas para que possa acompanhar o desenvolvimento avançado das tecnologias, introduzindoas no processo do ensino-aprendizagem para não se distanciar da realidade dos alunos. Segundo Martins (2011, p. 65) "ser professor em uma sociedade globalizada significa mais que transmissão de conteúdo. É necessário construir habilidades e competências para atuar num mundo recheado de tecnologias, privilegiando práticas transformadoras".

O professor necessita vincular as aulas tradicionais a inovadoras que despertem a imaginação dos alunos (BRASIL, 1998), passando a utilizar recursos didáticos como: trabalhos práticos com mapas virtuais, fotografias aéreas, imagens de satélite, entre outros recursos para obter maior eficácia no processo de ensino-aprendizagem e despertar a criatividade dos educandos. Nesta perspectiva, a BNCC, aponta que:

Para fazer a leitura do mundo em que vivem, com base nas aprendizagens em Geografia, os alunos precisam ser estimulados a pensar espacialmente, desenvolvendo o raciocínio geográfico. O pensamento espacial está associado ao desenvolvimento intelectual que integra conhecimentos não somente da Geografia, mas também de outras áreas (como Matemática, Ciência, Arte e Literatura). Essa interação visa à resolução de problemas que envolvem mudanças de escala, orientação e direção de objetos localizados na superfície terrestre, efeitos de distância, relações hierárquicas, tendências à centralização e à dispersão, efeitos da proximidade e vizinhança etc. (BRASIL, 2018, p. 357).

Com base nessas afirmações, tem-se que a Cartografia Escolar pode contribuir significativamente com as novas proposições ao ensino de Geografia no lugar, bem como estimular o desenvolvimento do raciocínio geográfico e do interdisciplinar pensamento espacial. Entretanto, ao estudar a Geografia, uma questão bastante significativa se refere a escala de análise. Deste modo, surge a necessidade de se delimitar o espaço geográfico pelo fato de o mesmo ser planetário. Esses níveis podem ser o local, regional, o nacional e o global. Assim, apresenta-se a importância do lugar, pelas relações sociais ocorrerem em lugares específicos e "a compreensão da realidade do mundo se dá a partir dos novos significados que assume a dimensão do espaço local" (CALLAI, 2014, p.69-70).

Nesse sentido, Callai (2013) apresenta que

A perspectiva de estudar o lugar por meio do trabalho com o município, tendo claro que o lugar não se explica por si mesmo, isto é, os fenômenos que acontecem no município, as relações entre os homens, o processo de organização do espaço local, não tem as explicações baseadas no próprio local apenas. É importante e necessário estabelecer ligações, buscar as explicações em nível regional, nacional e internacional/ mundial, inclusive (CALLAI, 2013, p.140). 
Estudando o lugar ou o espaço vivido, as explicações do mesmo podem serem externas, isto é, a organização espacial da população ou o comportamento econômico podem estar atrelados a uma polarização, envolvendo outras porções do território. Assim, demonstra a importância da transição de escalas na Geografia, onde o estudante tem um conhecimento da realidade onde reside, podendo em um primeiro momento: descrever, observar, comparar relacionar, correlacionar, concluir e ainda fazer relações de síntese entre o município de origem ou bairro, com outras regiões.

A comparação entre lugares distintos pode ser por meio de textos, gráficos ou documentos cartográficos, como imagens de satélite e mapas. Nesse sentido, Oliveira (2007, p.18), coloca que a Cartografia constitui "sem dúvida, um dos mais valiosos recursos do professor de Geografia" e a sua compreensão é fundamental ao entendimento do espaço geográfico que envolve a realidade do aluno.

Para se conseguir "ler" um mapa é necessário descobrir o que seus signos representam. Para que uma pessoa consiga interpretar todas as informações contidas em um mapa, é necessário que ela possua determinadas noções, dentre elas, segundo Simielli (1999), imagem bidimensional e tridimensional, visão oblíqua e vertical, proporção e escalas, bem como o alfabeto cartográfico (ponto, linha e área). Porém, para fazer uma leitura do mundo é fundamental o desenvolvimento de diversas linguagens, sem deixar de lado à cartográfica. Não basta apenas o aluno conseguir ler e escrever, também deve desenvolver uma linguagem cartográfica, não somente para realizar a interpretação de mapas prontos, mas, sim, do mapa construído no cotidiano, que leva em consideração aspectos sociais, econômicos e políticos, que estão inseridos na realidade do aluno.

Deste modo, o professor de Geografia deve desenvolver atividades para que seus alunos possuam competências cartográficas como: localização, orientação, legenda, proporção/escala, representação gráfica e cartográfica, visão vertical e oblíqua, imagem tridimensional e bidimensional. Essas noções antecedem a formação desses conceitos, ou melhor, estruturam o letramento cartográfico, cuja relevância está na compreensão, a partir de observações, percepções e representações que ele faz do espaço vivido (CASTELLAR, 2003). Uma eficiente alfabetização e letramento cartográfico permitem que os estudantes compreendam o lugar e, consequentemente, observem os atores e as intencionalidades impressas neste lugar. Assim, atividades que conduzam a leitura e produção de mapas, quando pensadas com propósito pedagógico, fomentam o interesse pelo lugar e as noções de pertencimento e de responsabilidade sobre o lugar.

Nesse sentido, o letramento cartográfico refere-se ao processo de domínio e aprendizagem de uma linguagem composta de signos, isto é, cores, formas, texturas e tonalidades, permitindo, assim, a elaboração e interpretação de mapas, além de desenvolver competências para a interpretação do espaço geográfico.

Entretanto, não basta que a criança apenas compreenda os signos presentes nos mapas, é necessário que o professor crie condições para que o aluno seja um leitor crítico de mapas ou um mapeador consciente (PASSINI, 1998), bem como um interventor responsável na realidade em que esta inserido, conforme ilustrado na Figura 2. Na mesma linha de pensamento, Souza (2014, p. 502) afirma que o "letramento cartográfico pode ocorrer de duas formas: ler o mapa e fazer o mapa, ambas as formas envolve o trabalho com a legenda, sua simbologia e representação". 


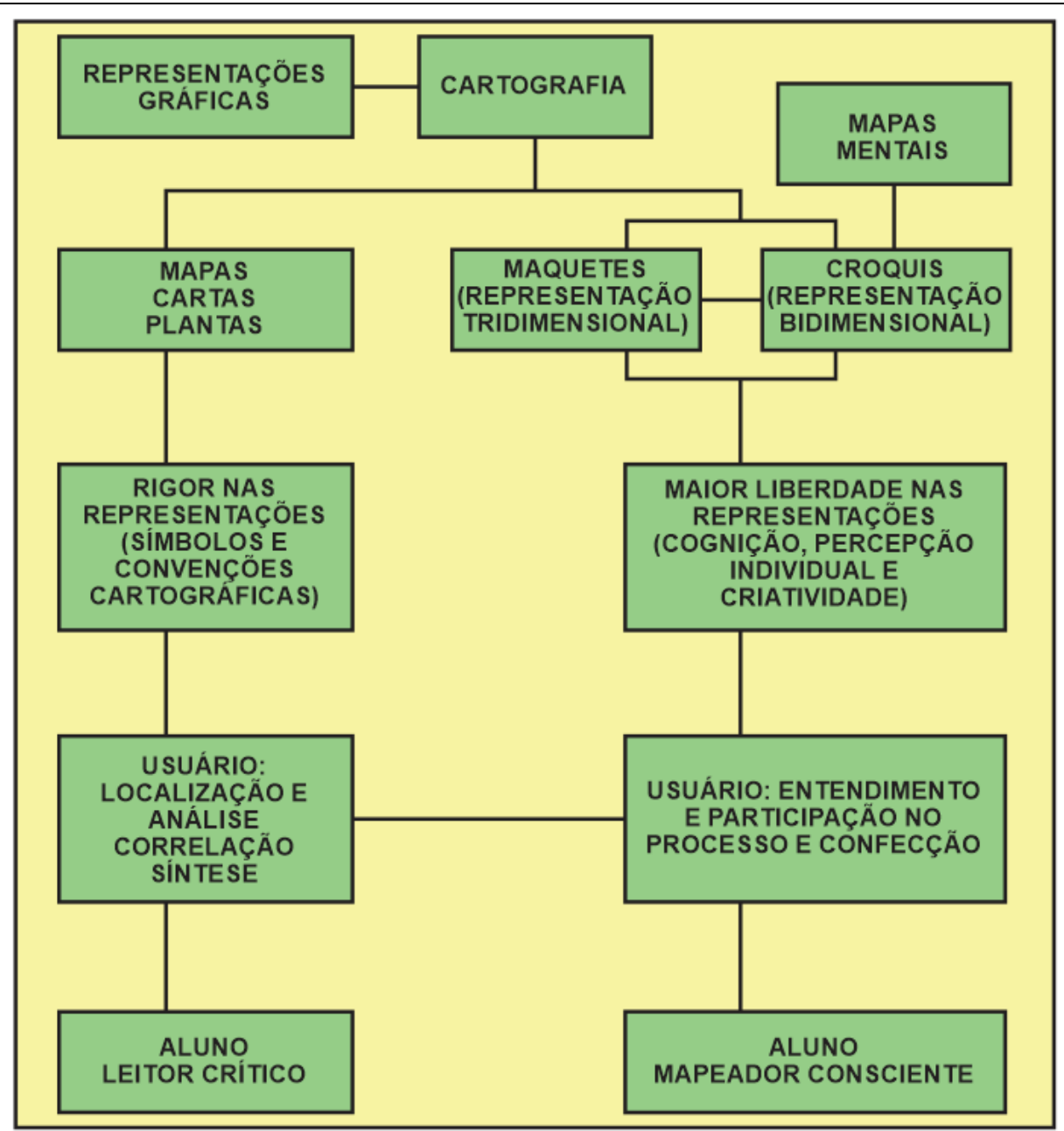

Figura 2 - Esquema sobre a relação de aluno leitor crítico e mapeador consciente. Fonte: SIMIELLI, 1999.

Ler o mapa significa possuir um conhecimento de mundo e correlacionar com sua realidade no lugar, o que é necessário para o entendimento dos fenômenos presentes em determinados locais e para a identificação dos seus significados, tornando-se um leitor crítico. Para um aluno mapeador consciente (elaboração do mapa) é uma tarefa mais complexa, visto que o discente precisa selecionar os dados mais importantes de determinado local, envolvendo uma seleção de signos para compor sua legenda, de modo a construir uma leitura e representação complexa e completa do lugar.

Da mesma maneira, fica evidente que

Para a realização da leitura crítica de um mapa é preciso que o educando compreenda que essa representação possui um vínculo direto com a representação do espaço, vivido ou ausente. Além disso, é preciso explorar os diversos elementos que compõe a representação cartográfica. Os símbolos, as cores e as relações que existem com o mundo. As representações cartográficas ultrapassam a mera descrição do espaço. São subsídios indispensáveis à tomada de decisão e a espacialização dos elementos que o compõem (BATISTA, 2015, p. 89).

A educação cartográfica é de extrema importância, pois auxilia a criança a entender o que o signo quer dizer na representação gráfica e correlacionar com o espaço 
vivido, pois o ser humano em sua natureza consegue criar diversas representações sobre onde vive. Segundo Ferreira:

A escola deve apresentar um ambiente que estimule o aluno a se apropriar da linguagem cartográfica e espera-se que, por meio da vivência e domínio da representação espacial, ele possa construir o seu conhecimento geográfico, partindo do concreto para atingir o abstrato, sempre observando e respeitando as etapas do desenvolvimento cognitivo (FERREIRA, 2012, p.40).

O domínio da linguagem cartográfica é necessário para que possam compreender o espaço onde se encontram e o lugar em que desenvolvem suas vidas. Ao observar essas informações no espaço vivido e conseguir visualizar esses elementos em uma representação bidimensional, a criança adquire um conhecimento que irá ser útil no decorrer de sua vida. O objeto principal do estudo da Geografia é a compreensão do espaço geográfico (CASTROGIOVANNI, 2000). Para facilitar a sua aprendizagem e entendimento, devem ser desenvolvidos conceitos pertinentes à localização, à orientação, ao lugar, à paisagem e ao território.

Assim, é possível observar a importância do ensino da Cartografia para que o aluno se torne um leitor e mapeador ativo, isto é, o estudante consiga representar o espaço a partir do seu mundo vivido e conhecido. Porém, a construção de um mapa envolve uma série de técnicas, como eleger os pontos mais importantes que serão representados, além de inserir as coordenadas, escala e orientação. Estes conhecimentos podem ser desenvolvidos utilizando recursos tecnológicos como meio didático no processo de ensino-aprendizagem (BRASIL, 1998).

A partir do exposto, apresentam-se metodologias para desenvolver noções cartográficas em sala de aula por meio de geotecnologias, fundamentais para a produção e interpretação de documentos cartográficos, remetendo ao ensino de Geografia representado no espaço vivido dos discentes. As variáveis são tipos de visão (horizontal, oblíqua e vertical), imagem bidimensional e tridimensional, alfabeto cartográfico, estruturação da legenda, proporção, escala e lateralidade (SIMIELLI, 2007).

Para a contextualização inicial dos tipos de visões, recomenda-se a demonstração, por meio de um exemplo simples, de que qualquer objeto, seja ele uma mesa, um armário ou uma árvore, podem serem visualizados com um determinado ponto de vista. Deste modo, uma cadeira pode ser vista horizontalmente (vista frontal) caso se esteja sentado (no chão) em sua frente. Nesse sentido, a visão frontal apresenta sempre um ponto cego (as costas do objeto). Se estivermos ajoelhados ao lado da cadeira, teremos uma vista oblíqua, de $45^{\circ}$ em relação a ela. Por fim, caso esteja-se em pé na frente da cadeira, temse uma visão vertical, onde a cadeira é vista através de uma perspectiva aérea. Também é possível utilizar o software Google Earth para ilustração das visões comentadas, representando um lugar ou uma edificação. Nesse sentido, o Google Earth o qual permite uma inclinação no que está sendo observando com um ângulo de $0^{\circ}$ (visão aérea) a $90^{\circ}$ (Google Street View). Com as construções em três dimensões do mencionado software, consegue-se ter uma visão oblíqua. A visão vertical e visão oblíqua são fundamentais na alfabetização cartográfica, pois todo mapa é uma visão vertical (SIMIELLI, 2007).

A mesma linha de raciocínio pode ser adotada para o tema proporção e escala, bem como para a elucidação das coordenadas geográficas (paralelos e meridianos/ latitude e longitude), é também possível para algumas ferramentas presentes no programa. A orientação espacial pode ser desenvolvida utilizando o mesmo software. Segundo Simielli (2007, p.92), “antes de qualquer coisa, o conceito de orientação espacial deve ser trabalhado pelas noções de lateralidade e referências". 
Para demonstrar a diferença de uma imagem bidimensional para tridimensional, o programa que pode ser utilizado é o StereoPhoto $\mathrm{Maker}^{2}$, que com o uso de um anáglifo é possível visualizar uma superfície em três dimensões (Figura 3). Para tal, são necessárias duas imagens com sobreposição longitudinal de aproximadamente $80 \%$. Ressalta-se que ambas imagens precisam estar localizadas na mesma latitude. As imagens podem ser obtidas das mais variadas fontes, como alvos fotografados com câmeras, aeronaves remotamente pilotada e imagens do Google Earth.

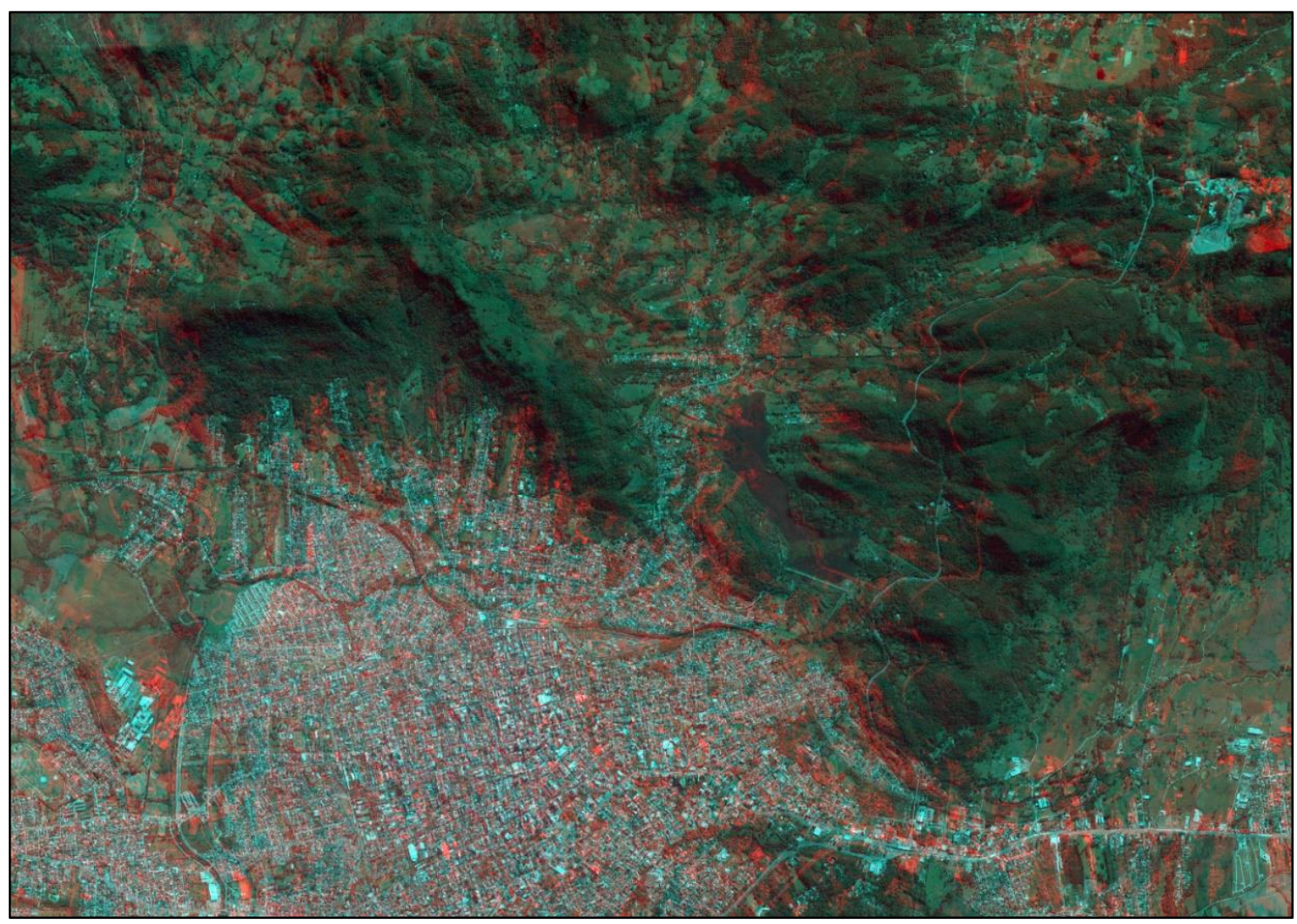

Figura 3 - Imagem tridimensional de Santa Maria, RS (indispensável uso do anáglifo). Fonte: StereoPhoto Maker (composição para anáglifo) e Google Earth Pro (Imagens).

A visualização do espaço geográfico em três dimensões numa perspectiva aérea é relevante quanto a sua abordagem. Neste caso, os conceitos que podem ser desenvolvidos no ensino de Geografia são pertinentes a hidrografia, identificando divisores de água e talvegues. Outra aplicação é quando se tem um extrato arbóreo de sentido linear e, ocupa as áreas de menor altitude se comparado com seu entorno, ou seja, um corpo de água acompanhado de mata ciliar. Isso, por exemplo, é observado a montante da Barragem do DNOS (parte superior da imagem) e no Arroio Cadena (centro da imagem). Além disso, o comportamento do relevo é um fator determinante para possíveis alagamentos. Nesse sentido, regiões com uma declividade baixa servem como planície de inundação de córregos. Ressalta-se que é necessário os estudantes possuírem um conhecimento teórico prévio para um melhor aproveitamento do recurso apresentado pelo professor em sala de aula (presencial ou remota). A ilustração fornecida pelo StereoPhoto Maker e o conhecimento do espaço vivido são de extrema importância para a interpretação do produto, podendo posteriormente, mencionar e indicar a relação com outras localidades.

Grande parte dos mapas utilizados no ensino de Geografia são de caráter temático. Esse tipo de mapa representa o que existe em determinada região, como por exemplo, o 
solo, a geomorfologia, a aptidão agrícola, entre outras inúmeras aplicações. O alfabeto cartográfico (ponto, linha e polígono) pode ser contextualizado por meio desses documentos e, assim, constituir-se em um facilitador do processo de ensino e aprendizagem na Geografia.

Um mapa de uso e ocupação da terra permite desenvolver conhecimentos acerca de paisagem, pois são representados elementos de caráter natural e artificial. Para a confecção de tal, utiliza-se uma imagem aérea do Google Earth, contendo o bairro em que se localiza a escola, e um papel vegetal, na qual identificaram as feições naturais (áreas arbóreas e campestres) e artificiais (alterações humanas e edificações) da paisagem no papel vegetal, em que atribuíram uma legenda para representar estas feições e indicar alguns elementos como escala e orientação.

O mapa de uso e ocupação da terra também pode ser construído em um ambiente digital, por exemplo, no software QGIS ${ }^{3}$. Dessa vez, é elaborado com base em uma imagem georreferenciada ${ }^{4}$, adquirida do Google Earth. Posteriormente, os discentes criaram shapefiles ${ }^{5}$ para delimitar a área urbanizada, a área arborizada e a de vegetação rasteira, bem como as ruas do bairro. Ao término desse procedimento, o mapa é finalizado no compositor de impressão e são acrescentadas algumas informações, como o título, as convenções utilizadas, a indicação do Norte e a escala.

Também é possível a elaboração do mapa com auxílio do receptor GPS. Com um trabalho de campo e uso de alguns receptores GNSS (GARMIN Etrex 30 ou GPS Essencials $^{6}$, por exemplo) onde marca-se pontos de interesse que servem de base para a confecção do mapa. A sua legenda apresenta as diferentes classes marcadas: área construída (prédios), ruas, área de campo e área de vegetação arbórea. Para isso, os pontos foram coletados em locais estratégicos, como por exemplo: início/final de ruas; arestas de áreas verdes, edificadas ou com predominância de vegetação rasteira. Em um segundo momento, ocorre a elaboração do mapa baseado nos pontos coletados na atividade de campo.

O complemento Points2one do QGIS permite criar linhas, linhas fechadas e polígonos, através de camadas de ponto. Sobre as geotecnologias, mais especificamente sobre receptores GNSS e SIG, essas ferramentas acabam facilitando ainda mais a possibilidade de aquisição e manuseio de dados geográficos, visto que possuem uma compatibilidade, gerando dessa maneira um rápido manejo de informações para a confeccionar diversos tipos e finalidades de mapas.

Nesse sentido, os alunos devem ser questionados durante a atividade de confecção para lembrarem da atividade pedagógica de como uma rua é representada (ponto, linha ou polígono) em um mapa, como em todo o seu processo de elaboração, visto que o aluno não é um depósito de conhecimentos memorizados, como se fosse uma gaveta. $\mathrm{O}$ aluno é capaz de pensar, refletir, discutir, ter opiniões, participar, decidir o que quer e o que não quer, que cabe ao professor questionar e respeitar suas decisões. Da mesma maneira que o anterior, finaliza-se no compositor de impressão. Todas essas atividades já foram testadas e apresentadas em textos como Rizzatti (2016 e 2018) e Batista (2015 e 2019), apresentando eficientes resultados com a alfabetização, letramento e multiletramento na Cartografia Escolar e que contribuem para o ensino da Geografia e o estudo do lugar.

Todas as atividades mencionadas, se corretamente contextualizadas pelo docente de Geografia, potencializam o estudo do lugar, pois levam o estudante a uma leitura e interpretação crítica do lugar, bem como a sua representação de forma consciente. Dessa forma, o estudo do lugar por meio de técnicas cartográficas tem significativa contribuição para o ensino de Geografia, fomentando a autonomia e a capacidade de intepretação dos estudantes frente a realidade em que estão inseridos e a sua relação com o global. 
Considera-se que as metodologias citadas são capazes de estimular os estudantes a pensarem o lugar com base em ferramentas interativas e tecnológicas, potencializando seu envolvimento com o ensino de Geografia e com a Cartografia Escolar, bem como levando-os ao entendimento da categoria de análise lugar, em especial, sob um viés localizacional e humanístico. Portanto, entender as diferentes abordagens do conceito de lugar permite relacionar com mais clareza os objetivos de estudo com as metodologias de ensino que devem ser adotadas.

O conhecimento sobre o lugar, por meio da Cartografia Escolar estimula os sentimentos de pertencimento e de engajamento entre os estudantes, fazendo-os intervirem com propriedade e consciência onde vivem. Portanto, as práticas citadas, além de motivarem o entendimento da Cartografia Escolar, também fomentam o estudo do lugar e, por conseguinte, estimulam a cidadania e o envolvimento dos estudantes com as causas que afeta o seu cotidiano.

\section{Considerações finais}

O mapa é um dos meios de comunicação da Geografia e sua produção está inserida no processo cartográfico, que envolve vários procedimentos, sendo o primeiro deles a delimitação do espaço geográfico (realidade), e, posteriormente, várias etapas, como a transformação de um mundo tridimensional para uma representação bidimensional, a redução (escala) e generalização, bem como a linguagem gráfica e cartográfica (simbologia). É necessário o aluno possuir oportunidades e habilidades na elaboração de mapas, para que se torne um mapeador consciente. As metodologias apresentadas nesse trabalho colaboraram para os estudantes desenvolverem aptidões referentes ao entendimento do processo de mapeamento, criação e utilização de dados geográficos, trabalhando ativamente com o alfabeto cartográfico na confecção dos mapas de uso e ocupação da terra.

Já a utilização de geotecnologias em sala de aula dinamiza a Cartografia através de técnicas digitais, tornando-a mais interativa através de cruzamento de informações. Também se tem o desenvolvimento de habilidades relativas à linguagem tecnológica e, mais restritamente, à computacional que é fundamental nos dias de hoje pelos avanços nas áreas de informação. Além disso, propicia aplicação de atividades escolares centradas no estudante, isto é, baseadas no estudo do espaço vivido, o que é bastante relevante, pois o mesmo tem um grande conhecimento do lugar onde reside e atrela isso com conhecimentos geográficos. Ainda objetiva estimular noções pertinentes ao alfabeto cartográfico, estruturação da legenda, proporção de escala e lateralidade, estimulando a percepção espacial dos discentes.

Além disso, o conceito de lugar construído após a década de 1970, tem uma importância primordial no contexto escolar. As noções dos estudantes sobre o espaço vivido devem ser aproveitadas e vinculadas a representação gráfica lugar. Um exemplo disso é analisar as características internas, os fluxos organizados pela população e sua relação com as vias de deslocamento. O ensino de Geografia por sua vez, através do lugar, propicia um grande leque de abordagens em sala de aula, além de contribuir para a formação da cidadania do corpo discente. 


\section{Referências}

ANDRADE, M. C. de. Geografia, ciência da sociedade: uma introdução à análise do pensamento geográfico. São Paulo: Atlas, 1987.

ARAÚJO, M. L. G. Ciência, Fenomenologia e Hermenêutica: diálogos da Geografia para os saberes emancipatórios. Tese (Doutorado em Geografia). Instituto de Geociências da UFMG, Belo Horizonte, 2007.

BATISTA, N. L. A Cartografia Escolar no processo de ensino-aprendizagem: o Hipermapa e sua utilização na Educação Ambiental, em Quevedos/RS. (Dissertação de Mestrado). Programa de PósGraduação em Geografia. Santa Maria: Universidade Federal de Santa Maria, 2015.

BATISTA, N. L. A Cartografia Escolar, Multimodalidade, multiletramentos para o ensino de Geografia na contemporaneidade. (Tese de Doutorado). Programa de Pós-Graduação em Geografia. Santa Maria: Universidade Federal de Santa Maria, 2019.

BRASIL, Ministério da Educação e do Desporto. Parâmetros Curriculares Nacionais. Brasília: MEC/SEF, 1998.

BRASIL. Ministério da Educação. Base Nacional Comum Curricular - Ensino Fundamental. Brasília, 2018.

BUZAI, G. D. Evolucion del Pensamiento Geografico hacia lá Geografia Global y la Neogeografia. In: FUENZALIDA, M.; BUZAI, G. D.; MORENO JIMÉNEZ, A.; GARCÍA DE LEÓN, A. "Geografía, geotecnología y análisis espacial: tendencias, métodos y aplicaciones". 1 ra ed., Santiago de Chile: Editorial Triángulo, 2015.

BUZAI, G. D. Geografia y tecnologias digitales del siglo XXI: uma aproximación a las nuevas visiones del mundo y sus impactos científico-tecnológicos. In: Scripta Nova. Vol. VIII, n. 170, 2004.

BUZAI, G. D. Impacto de la geotecnologia em el desarrollo teórico metodológico de la ciencia geográfica: hacia um nuevo paradigma em los albores del siglo XXI. Tese de Doutoramento. Facultad de Filosofía y Letras, Universidad Nacional de Cuyo, Mendonza, Argentina, 1998.

CALLAI, H. C. Estudar o lugar para compreender o mundo. In: CASTROGIOVANNI, A. C.; CALLAI, H. C.; KAERCHER, N. A. Ensino de Geografia: práticas e textualizações no cotidiano. 11. ed. Porto Alegre: Mediação, 2014.

CALlAI, H. C. O município: uma abordagem geográfica nos primeiros anos da formação básica. In: CAVAlCANTI, L. de S. Temas da Geografia na escola básica. Campinas, São Paulo: Papirus, 2013.

CAMARGO, J. C. G.; REIS JÚNIOR, D. F. da C. A filosofia (neo)positivista e a Geografia Quantitativa. In: VITTE, Antonio Carlos (org.) Contribuições à História e à Epistemologia da Geografia. Rio de Janeiro: Bertrand Brasil, 2007.

CASTELLAR, S. M. V; JULIASZ, P. C. S. Educação geográfica e pensamento espacial: conceitos e representações. Acta Geográfica, v. 1, p. 160-178, 2017. Disponível em:

https://revista.ufrr.br/actageo/article/view/4779/2427. Acesso em: 17 de janeiro de 2018.

CASTELLAR, S. M. VANZELLA. O letramento cartográfico e a formação docente: o ensino de geografia nas séries iniciais. In: Anais do $9^{\circ}$ Encuentro de Geógrafos de América Latina - Reflexiones y responsabilidades de la geografia em America Latina para el siglo XXI, Mexico, 2003.

CASTROGIOVANNI, A. C. Lugar, no-lugar y entre-lugar. Los ángulos del espacio turístico. Estudios y Perspectivas en Turismo. Buenos Aires: Centro de Investigaciones y Estudios Turísticos. v. 16, n. 1, 2007.

CASTROGIOVANNI, A. C. O lugar da geografia no entre-lugar do espaço turístico. Uma viagem complexa que ainda continua. In: Rosa dos Ventos, v. 1, 2009. 
CHAUÍ, M. Convite à filosofia. São Paulo: Ática, 1994.

CHRISTOFOLETTI, A. As características da nova geografia. In: Perspectivas Da Geografia. São Paulo: Difel, p.71-101. 1985a.

CHRISTOFOLETTI, A. As perspectivas dos estudos geográficos. In: Perspectivas Da Geografia. São Paulo: Difel, p. 11-36. 1985b.

CLAVAL, P. Epistemologia da Geografia - Florianopólis: Editora da UFSC, 2011.

CORRÊA, R. L. Região e organização espacial. São Paulo: Ática, 2003.

COSTA, F. R.; ROCHA, M. M. Geografia: conceitos e paradigmas-apontamentos preliminares. In: Revista de Geografia, Meio Ambiente e Ensino, v. 1, n. 2, 2011.

DE CAMPOS, R. R. Breve histórico do pensamento geográfico brasileiro nos séculos XIX e XX. Paco Editorial, 2011.

FERREIRA, L. N. B. A Alfabetização cartográfica e formação de professor: um aprendizado significativo. Americana: Centro Universitário Salesiano de São Paulo, 2012.

FERREIRA, L. F. Iluminando o Lugar: três abordagens (Relph, Buttimer e Harvey) In: Boletim Goiano de Geografia. Goiânia,v. 22, n.01. p. 43-72, 2002.

FERREIRA, A. B. H. Miniaurélio século XXI escolar: o minidicionário da língua portuguesa. rev. e ampl. Rio de Janeiro: Nova Fronteira, v. 2, 2001.

HOLZER, W. O lugar na geografia humanista. In: Revista Território, Rio de Janeiro, v. 4, n. 7, p. 67-78, 1999.

KUHN, T. S. A estrutura das revoluções científicas. São Paulo: Perspectiva, 1989.

LANG, S. Análise da paisagem com SIG / Stefan Lang, Thomas Blaschke; tradução Hermann Kux. São Paulo: Oficina de Textos, 2009.

MARTINS, R. E. M. A trajetória da geografia e o seu ensino no século XXI. In: TONINI, I. M. et al (Org.). O ensino de geografia e suas composições curriculares. Porto Alegre: UFRGS, p. 61-75, 2011.

MORAES, A. C. R. de. Geografia: pequena história crítica. São Paulo: Hucitec, 1987.

OLIVEIRA, L. Estudo metodológico e cognitivo do mapa. In: ALMEIDA, R. D. de. Cartografia Escolar. São Paulo: Contexto, 2007.

PISSINATI, M. C.; ARCHELA, R. S. Fundamentos da alfabetização cartográfica no ensino de Geografia. In: GEOGRAFIA (Londrina), v. 16, n. 1, p. 169-195, 2010.

POPPER, K. R. A lógica da pesquisa científica. Editora Cultrix, 1972.

RIZZATTI, M. Cartografia Escolar, geotecnologias e a Teoria das Inteligências Múltiplas: a construção de conhecimentos geográficos no ensino fundamental. (Trabalho de Graduação) - Universidade Federal de Santa Maria, Centro de Ciências Naturais e Exatas, Departamento de Geociências, Curso de Geografia - Licenciatura Plena, RS, 2016.

RIZZATTI, M. A cartografia escolar e as inteligências múltiplas no ensino de Geografia: contribuições das geotecnologias no Ensino Fundamental. (Dissertação de Mestrado). Programa de Pós-Graduação em Geografia. Santa Maria/RS: Universidade Federal de Santa Maria, 2018.

RODRIGUES, A. de J. Geografia: introdução à ciência geográfica. São Paulo: Avercamp, 2008. 
SANTOS, M. Por uma geografia nova: da crítica de geografia a uma geografia. $3^{a}$ ed. São Paulo: HUCITEC, 1986.

SAUER, C. A morfologia da paisagem. In: CORRÊA, R. L.; ROSENDAHL, Z. (Org.). Paisagem, tempo e cultural. Rio de Janeiro: EdUERJ, 1998.

SIMIELLI, M. E. R. Cartografia no ensino fundamental e médio. In: CARLOS, Ana Fani Alessandri (org.). A Geografia na sala de aula. São Paulo: Contexto, 1999.

SIMIELLI, M. E. R. O mapa como meio de comunicação e a alfabetização cartográfica. In: ALMEIDA, R. D. de. Cartografia Escolar. São Paulo: Contexto, 2007.

SOUZA, V. L. C. A. Importância do letramento cartográfico nas aulas de Geografia. In: Anais do Congresso Latino-Americano de Compreensão Leitora-Jaime Cerrón Palomino (ISSN 2359-5558), p. 499-506, 2014.

TUAN, Y. Espaço e Lugar: a perspectiva da experiência. São Paulo: DIFEL, 1983.

TUAN, Y. Topofilia um estudo da percepção, atitudes e valores do meio ambiente. DIFEL, 1980.

TUAN, Y. Espaço e Lugar: a perspectiva da experiência. Trad. Lívia de Oliveira. Londrina: Eduel, 2013.

\section{Notas}

${ }^{1}$ Para Karl R. Popper (1972, p. 27), a indução é caracterizada "caso ela conduza de enunciados singulares (por vezes também enunciados particulares), tais como descrições dos resultados de observações ou experimentos, para enunciados universais, tais como hipóteses ou teorias".

${ }^{2} \mathrm{O}$ StereoPhoto Maker é um programa livre e tem a funcionalidade de editor de imagens estéreo versátil e pode alinhar automaticamente centenas de imagens e permite gerar um anáglifo para visualização de imagens em terceira dimensão (3D).

${ }^{3}$ QGIS é um sistema de informação geográfica (SIG) gratuito e licenciado sob a General Public License (GNU), na qual permite edição, visualização e análise de dados geográficos.

${ }^{4} \mathrm{O}$ Georreferenciamento designa o procedimento da transformação de um conjunto de dados de imagem em um sistema de referência espacial, com suas coordenadas conhecidas (LANG, 2009).

${ }^{5}$ Shapefile é um formato bastante corrente para dados vetoriais. Inclui somente objetos da mesma dimensão espacial, formando, assim, um tema pontual, linear ou polígono (LANG, 2009).

${ }^{6}$ GPS Essentials é a ferramenta GPS mais completo para o sistema operacional Android. Com o aplicativo pode-se navegar, gerenciar pontos de passagem, trilhas, rotas, construir o seu próprio computador de bordo. 